\title{
A NEW SPECIES OF GONGYLOSOMA (SQUAMATA: COLUBRIDAE) FROM PULAU TIOMAN, WEST MALAYSIA
}

\author{
L. Lee Grismer ${ }^{1,4}$, Indraneil Das ${ }^{2}$, and Tzi Ming Leong ${ }^{3}$ \\ ${ }^{1}$ Department of Biology, La Sierra University, Riverside, CA 92515-8247, USA \\ ${ }^{2}$ Institute of Biodiversity and Environmental Conservation, Universiti Malaysia Sarawak, 94300, \\ Kota Samarahan, Sarawak, Malaysia \\ ${ }^{3}$ Department of Biological Sciences, National University of Singapore, Kent Ridge, Singapore 119260
}

\begin{abstract}
A new species of Gongylosoma is described from Pulau Tioman, a small island $38 \mathrm{~km}$ off the southeast coast of Pahang, West Malaysia, in the South China Sea. This species differs from all other Gongylosoma in having a single, enlarged, posterior temporal; chinshields of equal size; and a thin nuchal band that contacts a vestigial vertebral stripe. The new species forms a clade with G. nicobariense from the Nicobar Islands and G. longicauda from Borneo, Java, and Sumatra and is the sister species of the latter.
\end{abstract}

Key words: Biogeography; Gongylosoma; Liopeltis; Malaysia; Pulau Tioman

The COLUBRID genus Gongylosoma Fitzinger 1843 currently contains four southeast Asian species (Das, 1999; de Haas, 1950; de Rooij, 1915; Leviton, 1964) and an additional undescribed form from Borneo (Gongylosoma "Borneo") listed under the genus Liopeltis Fitzinger 1843 (Stuebing and Inger, 1999). Species of Gongylosoma are generally small, secretive, forest floor inhabitants that, with the exception of G. baliodeirum, are not commonly seen. Consequently, many species are known from fewer than 10 specimens. Leviton (1964) provided compelling character support from a number of anatomical systems as evidence for separating Gongylosoma from Liopeltis, which most authors have followed (i.e., Das, 1999; Das et al., 1998; David and Vogel, 1996) but others have not (Grandison, 1978; Manthey and Grossmann, 1997; Stuebing and Inger, 1999; Tweedie, 1983). Species of Gongylosoma range from Myanmar and Thailand southward through peninsular Malaysia, Singapore, and the Nicobar Islands to Sumatra, Borneo, Java, and their associated islands.

We report here a newly discovered population of Gongylosoma from Pulau Tioman, a small $\left(133.6 \mathrm{~km}^{2}\right)$ island $38 \mathrm{~km}$ off the southeast coast of the state of Pahang, West Malaysia, in the South China Sea (Fig. 1). Pulau Tioman has been the focal point of recent herpetological investigations (e.g., Das and Lim, 2000; Grismer et al., 2002a,b,c;

\footnotetext{
${ }^{4}$ Correspondence: e-mail, lgrismer@lasierra.edu
}

Leong and Grismer, 2002; Lim and Lim, 1999) that have resulted in the discovery of several new island records and species (see Grismer et al., 2002a for a summary). The Gongylosoma reported here is sufficiently distinct from all other congeneric taxa in both squamation and color pattern that we herein describe it as a new species.

\section{Materials and Methods}

All species of Gongylosoma were examined (Appendix I) and compared with the single, new specimen from Pulau Tioman. Scale counts included preoculars, postoculars, supralabials, number of supralabials contacting the eye, infralabials, anterior and posterior temporals, ventrals, and subcaudals (Table 1). Measurements included eye diameter (ED); head length (HL) from the union of the posteromedial corners of the parietals to the tip of the snout; head depth (HD) from the dorsal surface of the head to the ventral surface of the jaw immediately posterior to the eye; and snout length (SL) from the anterior margin of the eye to the tip of the snout. All measurements were made with vernier calipers to the nearest $0.1 \mathrm{~mm}$. Color pattern characters were taken from preserved specimens, color photographs in Stuebing and Inger (1999), and 35-mm color transparencies (Appendix I). Scale terminology follows Stuebing and Inger (1999). Museum acronyms follow Leviton et al. (1985) except that we retain ZRC (Zoological Reference Collection) for USDZ, which follows conventional usage. 